\section{Maximal Exercise Heart Rate}

James E. Turner

Department for Health, University of Bath, Bath, UK

\section{Synonyms}

$\mathrm{HR}_{\max }$; Tachycardia

\section{Definition (and Description)}

Maximum exercise heart rate refers to the highest or fastest rate at which the heart can beat during exercise and is expressed as the number of heartbeats per unit of time, usually beats per minute (bpm).

Heart rate increases linearly with oxygen consumption and, therefore, exercise intensity. Maximum exercise heart rate is most accurately recorded upon volitional exhaustion and termination of a maximal exercise stress test. Maximal exercise heart rate declines with aging; therefore, several formulas are also available to estimate maximal heart rate on the basis of age. The most widely used formula; $\mathrm{HR}_{\max }=220$ - age (in years), provides a rough approximation. However, due to lower maximal heart rates among well-trained individuals, several populationspecific formulas also exist. In behavioral research, estimated or measured maximal exercise heart rate can be used to prescribe exercise (e.g., walking speed) based upon the relationship between oxygen consumption, heart rate, and exercise intensity.

\section{Cross-References}

Exercise Stress Test

\section{References and Further Readings}

McArdle, W. D., Katch, F. I., \& Katch, V. L. (2001). Exercise physiology. Energy, nutrition and human performance (5th ed.). Baltimore: Lippincott Williams \& Wilkins.

Whaley, M. H., Brubaker, P. H., \& Otto, R. M. (Eds.). (2006). ACSM's guidelines for exercise testing and prescription (7th ed.). Baltimore: Lippincott Williams $\&$ Wilkins. 